\title{
ESTRATÉGIAS PRODUTIVAS E REPRODUÇÃO SOCIECONÔMICA DA AGRICULTURA DE PORTO VERA CRUZ, RIO GRANDE DO SUL
}

\author{
PRODUCTIVE STRATEGIES AND SOCIECONOMIC REPRODUCTION OF \\ AGRICULTURE IN PORTO VERA CRUZ, RIO GRANDE DO SUL
}

\section{ESTRATEGIAS PRODUCTIVAS Y REPRODUCCIÓN SOCIECONÓMICA DE LA AGRICULTURA EN PORTO VERA CRUZ, RIO GRANDE DO SUL}

\author{
José Tobias Marks Machado ${ }^{1}$ \\ ORCID: 0000-0002-1725-7166 \\ Lovois de Andrade Miguel $^{2}$ \\ ORCID: 0000-0001-7194-6774 \\ Jeferson Tonin ${ }^{3}$ \\ ORCID: 0000-0003-3410-7247
}

Submissão: 05/08/2020 / Aceito: 01/10/2020 / Publicado: 04/02/2022.

\begin{abstract}
Resumo
O artigo teve como objetivo analisar as estratégias produtivas e as possibilidades de reprodução social dos diferentes tipos de agricultores que compõem a agricultura do município de Porto Vera Cruz, RS. Como referencial teórico o artigo fez uso da Abordagem dos Sistemas Agrários, que metodologicamente se desdobra na AnáliseDiagnóstico de Sistemas Agrários (ADSA). A partir da análise efetuada foi possível perceber que a história agrária local se caracteriza por ter sofrido uma ocupação tardia e desorganizada. $\mathrm{O}$ afastamento geográfico do município e a exiguidade do meio físico foram também aspectos que dificultaram o desenvolvimento passado e incidem sobre o desenvolvimento contemporâneo da agropecuária municipal. Atualmente, cinco tipos de agricultores conformam a agricultura porto vera-cruzense e apresentam distintas estratégias de produção. São eles o Agricultor Familiar Diversificado, Agricultor Familiar produtor de Leite, Agricultor Familiar produtor de Gado de Corte e Leite, Agricultor Familiar produtor de Suínos e Gado de Corte e o tipo Empreendedor. Em termos econômicos as quatro tipologias de agricultores familiares apresentam renda próxima ao nível de reprodução social estipulado, sendo que cada tipo apresenta problemáticas específicas que podem restringir as suas possibilidades de reprodução no futuro. No entanto, os Agricultores Familiares produtores de Leite e os produtores de Gado de Corte e Leite são aqueles que apresentam a reprodução mais ameaçada, por limitações que perpassam o tamanho dos seus estabelecimentos e a falta de sucessão familiar, respectivamente. Por fim, cabe destacar que
\end{abstract}

\footnotetext{
${ }^{1}$ Mestre em Desenvolvimento Rural (PGDR/UFRGS). Professor da Universidade Federal Rural da Amazônia (UFRA) e doutorando em Desenvolvimento Rural (PGDR/UFRGS). E-mail: tobias.machado@ufra.edu.br ${ }^{2}$ Doutor em Agricultura Comparada e Desenvolvimento Agrícola (INA P-G). Professor da Universidade Federal do Rio Grande do Sul (UFRGS).E-mail: lovois@ufrgs.br

${ }^{3}$ Mestre em Desenvolvimento Rural (PGDR/UFRGS). Professor da Universidade Federal do Amazonas (UFAM) e doutorando em Desenvolvimento Rural (PGDR/UFRGS). E-mail: jefersontonin@ufam.edu.br
} 
a análise empreendida e a abordagem utilizada podem ser úteis ao planejamento e ao desenvolvimento rural.

Palavras-chave: Desenvolvimento Rural, Sistemas Agrários, Tipologias, Agricultura Familiar, Análise Econômica.

\begin{abstract}
The objective of the article was to analyze the productive strategies and the possibilities of social reproduction of the different types of farmers, in Porto Vera Cruz, RS. As a theoretical reference, the article used the Agrarian Systems Approach. The method consisted of the "Analysis-diagnosis of Agricultural Systems" (ADSA). On the one hand it was possible to verify that the local agrarian history is characterized by a late and disorganized occupation. On the other hand, it was verified that the geographical distance from the municipality and the smallness of the physical environment were aspects that hindered the development of agriculture. Currently, five types of farmers exist in Porto Vera Cruz, and present different production strategies. These are: Family Farming Diversified, Family Farming Milk Producer, Family Farming Cattle and Milk Producer, Family Farming Swine and Cattle Producer and Entrepreneurs. In economic terms, the four types of family farmers have income close to the level of social reproduction. However, each type presents specific problems. Family farmers who produce milk and producers of beef cattle and dairy cattle are those with the most threatened social reproduction. This situation stems from the limitations that pervade the size of their farms and the lack of family succession, respectively. Finally, the analysis and approach used can be useful for rural planning and rural development.
\end{abstract}

Keywords: Rural Development, Agrarian Systems, Typologies, Family Farming, Economic Analyze.

\title{
Resumen
}

El artículo tuvo como objetivo analizarlas estratégias productivas y lãs posibilidades de reproducción social de los diferentes tipos de agricultores que conformanla agricultura en el municipio de Porto Vera Cruz, RS. Como referencia teórica, el artículo utilizóel Enfoque de Sistemas Agrarios, que se desarrolla metodológicamente en el Análisis-Diagnóstico de Sistemas Agrarios (ADSA). Del análisis realizado fue posible notar que la historia agraria local se caracteriza por haber sufrido una ocupación tardía y desorganizada. Junto conesto, la distancia geográfica del municipio y el entorno físico limitado fueron aspectos que obstaculizaron el desarrollopasado y afectaron el desarrollo contemporáneo de la agricultura municipal. Actualmente, cinco tipos de agricultores conforman la agricultura Porto Vera-Cruzense y presentan diferentes estrategias de producción. Ellos son el granjero familiar diversificado, el granjero familiar que produce leche, el granjero familiar que produce carne de res y lácteos, el granjero familiar que produce carne de cerdo y res y el tipo emprendedor.

En términos económicos, los cuatro tipos de agricultores familiares tienen ingresos cercanos al nivel estipulado de reproducción social, presentando cada tipo problemas específicos que pueden restringir sus posibilidades de reproducción en el futuro. Sin embargo, los Agricultores Familiares productores de Leche y los productores de Carne de Vacuno y Ganado Lechero son los que tienen la reproducción más amenazada, debido a las limitaciones que invaden el tamaño de sus establecimientos y la falta de sucesión familiar, respectivamente. Finalmente, cabe señalar que el análisis realizado y el enfoque utilizado pueden ser útiles para la planificación y el desarrollo rural. 
Palabras clave: Desarrollo rural, sistemas agrarios, tipologías, agricultura familiar, análisis económico.

\section{INTRODUÇÃO}

A compreensão das condições de existência e as particularidades da evolução, diferenciação e reprodução das sociedades agrárias, e suas respectivas formas de agricultura, constitui-se de longa data como um desafio para as diferentes áreas do conhecimento que se preocupam com a promoção de ações em prol do desenvolvimento rural (MIGUEL, 2014). Dentre as diversas perspectivas analíticas, a Abordagem dos Sistemas Agrários, apresentada por Mazoyer e Roudart (2010), caracteriza-se por ser uma ferramenta que busca apreender a complexidade e a heterogeneidade que perpassa o desenvolvimento da agricultura (MIGUEL, 2014, 2018; SILVA NETO, 2014) Utilizando uma visão sistêmica e multidisciplinar, esta abordagem teórica busca realizar uma interpretação histórica e evolutiva do desenvolvimento da agricultura (DUFUMIER, 2010; MAZOYER; ROUDART, 2010).

De acordo com Miguel (2018), ao empreender uma análise evolutiva, a Abordagem dos Sistemas Agrários se empenha no estudo das dinâmicas passadas, do desenvolvimento atual e das tendências futuras de uma determinada agricultura. Para isso, a abordagem realiza um exame amplo e profundo das relações entre as Unidades de Produção Agropecuária e o meio que as envolve, em que fenômenos sociais, econômicos e ambientais são considerados (MIGUEL, 2018; NEUMANN; FIALHO, 2009; SILVA NETO, 2014). Devido a tais características, o referencial teórico metodológico da abordagem tem servido como instrumento para diagnóstico de realidades rurais complexas e para a proposição de ações em prol do desenvolvimento rural (BENTO et al., 2017; DEON; AZEVEDO; NETTO, 2017; DUFUMIER, 2010; GUANIZIROLI, 1999; LIMA et al., 2005, 2016; MIGUEL, 2018; SILVA NETO, 2014; SILVA NETO; BASSO, 2015a).

A partir do uso do referencial teórico da Abordagem dos Sistemas Agrários, este estudo tem como objetivo analisar as estratégias produtivas e as possibilidades de reprodução social dos diferentes tipos de agricultores do município de Porto Vera Cruz, localizado na região noroeste do estado do Rio Grande do Sul. Para tanto, além desta introdução e das considerações finais, o artigo está dividido em mais cinco seções. Em seguida, na segunda seção, é apresentado o referencial teórico utilizado para a realização 
deste trabalho. A terceira seção expõe o método de estudo. A partir da quarta seção são discutidos os resultados da pesquisa. $\mathrm{Na}$ seção quatro a descrição das características históricas e ambientais é feita, para que posteriormente, nas outras duas seções, os atributos produtivos e sociais, e os resultados econômicos dos diferentes tipos sejam apresentados. As considerações finais apontam para as tendências e para as problemáticas que envolvem cada tipo de agricultor identificado pelo estudo.

\section{REFERENCIAL TEÓRICO ANALÍTICO}

Segundo Mazoyer e Roudart (2010), a Abordagem dos Sistemas Agrários pode ser definida como um ferramental que permite apreender a complexidade de cada forma de agricultura e de perceber, em grandes linhas, as transformações históricas e a diferenciação geográfica das agriculturas empreendidas pelo homem. Dessa forma, para os autores “(...) cada sistema agrário é a expressão teórica de um tipo de agricultura, historicamente constituído e geograficamente localizado" (p. 71). Mazoyer e Roudart (2010) destacam ainda que, ao conceber a agricultura como um objeto complexo e por consequência em termos de sistema, o seu funcionamento é analisado como uma combinação de funções interdependentes e complementares, que asseguram a circulação da matéria, da energia, e tratando-se de um objeto econômico do valor. A análise sistêmica desse objeto complexo, permite sua decomposição em dois subsistemas principais, o "ecossistema cultivado" e o "sistema social produtivo". Ambos formam o que se convencionou intitular de Unidade de Produção Agropecuária (UPA). Já o Sistema Agrário, conceito de maior amplitude e abrangência, pode ser explicitado como sendo a própria expressão de um conjunto de UPAs, de um determinado local em um dado período do tempo.

$\mathrm{O}$ ecossistema cultivado corresponde à forma como se organizam os constituintes físicos, químicos e biológicos do Sistema Agrário, perpassando assim às modificações impostas aos ecossistemas naturais para que a sociedade, nele instalada, obtenha produtos e serviços de seu interesse (SILVA NETO; BASSO, 2015a). O sistema social produtivo, segundo Mazoyer e Roudart (2010), é composto por meios humanos (força de trabalho, conhecimento e o savoir-faire), meios inertes (instrumentos e equipamentos produtivos) e meios vivos (plantas cultiváveis e animais domesticados), que dispõem a população 
agrícola de determinada época, para renovar e explorar a fertilidade do ecossistema cultivado.

O estudo da organização, do funcionamento e das inter-relações desses dois subsistemas principais é que permitem o entendimento da dinâmica de um Sistema Agrário. Sendo que tal inter-relação se desdobra em um ecossistema historicamente constituído por meio da sua exploração e renovação via um sistema social produtivo. Com isso, costuma-se dizer que há desenvolvimento geral quando todos os tipos de exploração, ou seja, todas as UPAs progridem, adquirindo novos meios de produção, desenvolvendo suas atividades, aumentando suas dimensões econômicas e seus resultados produtivos. O desenvolvimento é desigual quando certas UPAs progridem muito mais rapidamente que outras. No entanto, ele é contraditório quando algumas unidades progridem ao passo que outras estão em crise e regridem. A crise de um sistema agrário é considerada geral quando todos os tipos de unidades de produção regridem e tendem a desaparecer. Chama-se ainda de "Revolução Agrícola" a mudança no Sistema Agrário, de modo que ao longo do tempo podem surgir, desenvolver-se, declinar e se suceder, em uma dada região, Sistemas Agrários que constituem as etapas de uma série evolutiva própria (MAZOYER; ROUDART, 2010; MIGUEL, 2014, 2018)

Dessa forma, Miguel (2014) salienta que os instrumentos intelectuais mobilizados pela Abordagem dos Sistemas Agrários apresentam uma função heurística de apreender, analisar, compreender e explicitar uma realidade complexa, extremamente diversificada e constantemente mutável. Porém, o autor destaca que se metodicamente explicada a organização e o funcionamento de um Sistema Agrário, é possível conceber um tipo de arquétipo que proporciona uma imagem coerente e harmoniosa da agricultura ao longo do tempo. Além do conceito de Sistema Agrário, a abordagem apresenta outros conceitos de cunho sistêmico. Tais conceitos possuem uma abrangência micro analítica e são úteis aos estudos dos processos produtivos, sociais e técnicos, que ocorrem no interior das Unidades de Produção Agropecuária (MIGUEL, 2018).

Assim, dentro de um Sistema Agrário a combinação de meios de produção não é homogênea. As peculiaridades do ecossistema cultivado e as características do sistema social produtivo variam segundo o estatuto social, a localização da UPA e a acumulação de riquezas de cada agricultor. Em vista das características do ecossistema cultivado e da disponibilidade de determinados meios de produção dentro de uma UPA, bem como em 
virtude de aspectos socioeconômicos exteriores, como o tipo de política agrícola e as características dos mercados vigentes, os diferentes agricultores tomam decisões e colocam em prática um determinado "sistema de produção" (DUFUMIER, 2010; MIGUEL, 2018; SILVA NETO; BASSO, 2015a)

Nos limites da UPA, o sistema de produção pode ser definido como a combinação dos diversos fatores produtivos disponíveis, que conformam subsistemas e que são categorizados como "sistemas de cultivo", "sistemas de criação" e "sistemas de transformação". Os sistemas de cultivo são definidos com base nas parcelas, ou grupos de parcelas, trabalhados de maneira homogênea, seguindo as mesmas sucessões de culturas e itinerários técnicos. Já os sistemas de criação, são formados por plantéis de animais que recebem um mesmo tipo de manejo. Por fim, os sistemas de transformação dos produtos agropecuários são as subunidades, em que através de técnicas e conhecimentos dos agricultores os produtos primários são processados (DUFUMIER, 2010; MIGUEL, 2018).

Além do sistema produtivo, e dos três subsistemas que o compõe, a UPA é ainda formada pelo "sistema social", que é composto pelos objetivos dos produtores. Tal sistema compreende as práticas sociais, as representações, as estratégias e os objetivos manifestados pelos agricultores e suas famílias (MIGUEL, 2018; WIVES, 2008). Pode se dizer assim, que a partir da interação entre o sistema social e o sistema produtivo são desenvolvidas estratégias produtivas, as quais visam a reprodução social de uma UPA (MIGUEL et al., 2018). Tal como tratado por Silva Neto, 2016b), a reprodução social deve ser entendida como a capacidade mínima de geração de riquezas que a unidade deve possuir, para que sua reprodução ao longo do tempo seja assegurada. Por fim, como tratado por Miguel (2018), a Unidade de Produção Agropecuária deve ser compreendida como um objeto resultante da interação entre o sistema de produção e o sistema social, que possuem tanto uma interação mútua, como também são influenciadas pelo contato contínuo com elementos do meio externo, tais como a conjuntura macroeconômica e as mudanças ambientais, por exemplo.

\section{PROCEDIMENTOS METODOLÓGICOS}

Segundo Neumann e Fialho (2009) e Silva Neto e Basso (2015), a operacionalização da Abordagem dos Sistemas Agrários se dá através da realização da 
Análise-Diagnóstico de Sistemas Agrários (ADSA). Cinco são as suas etapas metodológicas, sendo estas (i) o zoneamento agroambiental regional, (ii) a caracterização histórica da agricultura, (iii) a construção tipologias de agricultores, (iv) a análise dos sistemas de produção (v) e a análise da dinâmica da agricultura, objetivando a proposição e execução de ações para o desenvolvimento (DUFUMIER, 2010; MIGUEL, 2018).

As duas primeiras etapas se relacionam a uma apreensão da interação entre os aspectos ambientais e sociais e os seus desdobramentos na dinâmica de desenvolvimento da agricultura. Já a caracterização dos tipos e o estudo aprofundado dos sistemas de produção, são duas partes que privilegiam a análise de aspectos agronômicos e socioeconômicos das Unidades de Produção Agropecuária, estando assim diretamente relacionadas à realidade atual. Por último, com base nas quatro etapas anteriores, análises e proposições para o desenvolvimento futuro da agricultura podem ser realizadas. Para que o objetivo deste trabalho fosse alcançado, todas as etapas foram efetuadas. Contudo, dado o escopo analítico do estudo, o exame da dinâmica da agricultura não objetivou a proposição de projetos. Considerando que o objetivo do estudo repousou sobre a análise das estratégias produtivas e das possibilidades de reprodução social da agricultura, a pesquisa se debruçou, sobretudo, na construção de tipologias e no estudo agronômico e socioeconômico dos sistemas de produção.

Dessa forma, inicialmente foi realizado o zoneamento agroambiental do município, que consistiu na delimitação e caracterização do espaço empírico estudado. Através da técnica de leitura da paisagem, foram identificados os principais ecossistemas cultivados, as unidades de relevo, os tipos de solos e as principais formações vegetais do município. A partir da realização de incursões no território de Porto Vera Cruz e do uso de recursos cartográficos, foi possível delimitar e compreender as principais especificidades e diferenciações da paisagem agrária. Posterior ao conhecimento das diferentes zonas agroambientais, a reconstrução da história da agricultura foi realizada. Deve ser salientado que para este estudo, não foi efetuada uma análise aprofundada dos diferentes Sistemas Agrários que se sucederam ao longo do tempo. A análise privilegiou a dinâmica histórica da agricultura no período mais recente, averiguando o desenvolvimento agrário do município e o processo de diferenciação social entre os agricultores, a partir dos primórdios de sua colonização. Desse modo, a caracterização histórica privilegiou inicialmente uma revisão bibliográfica sobre a história agrária e política do município e da região noroeste do 
Rio Grande do Sul. Posteriormente, foram realizadas dez entrevistas com "informantesqualificados", durante o mês de setembro de 2016. Seguindo ao recomendado por Miguel (2018), foram considerados como tais informantes agricultores e demais indivíduos que possuíam conhecimento sobre a história regional, ou ainda vivências das principais transformações da agricultura local.

A partir do reconhecimento da história agrária municipal e dos processos de diferenciação social, os produtores foram classificados em tipos. A agregação se deu em função das categorias sociais e sistemas de produção colocados em prática. Tratando-se das características sociais, três são as categorias básicas de agricultores utilizados nas pesquisas que realizam a Análise-Diagnóstico de Sistemas Agrários, sendo estas "Agricultor Familiar", "Agricultor Patronal" e "Empreendedores" (MIGUEL, 2010; SILVA NETO, 2014). A categoria Agricultor Familiar tem como característica básica desenvolver sistemas de produção que se valem do trabalho majoritariamente familiar, de modo que o seu funcionamento não depende do uso de mão de obra contratada. Já a categoria social dos Empreendedores, tem como característica reunir indivíduos que investem na agricultura, e assim como os membros da sua família não trabalham diretamente nas atividades agropecuárias. O funcionamento das unidades de produção dos Empreendedores é assegurado integralmente pelo uso de mão de obra contratada. No âmbito deste estudo, não foi identificada a existência de agricultores patronais.

Reconhecidos as categorias sociais, a análise aprofundada dos seus respectivos sistemas de produção foi efetuada. Nesta etapa foi realizada a caracterização agronômica e socioeconômica dos sistemas de produção. A avaliação agronômica buscou compreender a coerência dos sistemas de produção adotados e as razões que levam o agricultor a optar por um ou outro modo de produzir. Dito de outra forma, este exame buscou compreender as razões para o desenvolvimento de determinada estratégia produtiva. Junto a análise agronômica, foi realizada a avaliação socioeconômica dos sistemas de produção encontrados. Através do cálculo da Renda Agrícola (RA) a avaliação socioeconômica buscou averiguar o potencial de geração de riquezas dos sistemas de produção para cada tipo de agricultor. Abaixo é apresentada a equação para mensuração deste indicador.

$$
\text { RA = PBT - CI - D - J - S - A - I }
$$

PBT: Produto Bruto Total; CI: Consumo Intermediário; D: Depreciação dos fatores de produção J: Juros; A: Arrendamentos; S: Salários; I: Impostos e taxas pagas ao Estado 
Todos as variáveis foram medidas considerando o resultado econômico de um ano agrícola e seguiram as recomendações apresentadas na bibliografia relacionada à avaliação econômica de sistemas de produção (DUFUMIER, 2010; GUANIZIROLI, 1999; LIMA et al., 2005; MIGUEL, 2010; SILVA NETO, 2016b). A partir do cálculo da renda agrícola, foram elaborados modelos lineares que descrevem a variação do resultado econômico global dos sistemas de produção, em relação a superfície agrícola útil (SAU) ${ }^{4}$ disponível pela a UPA. A modelagem dos resultados econômicos tem como principal vantagem permitir uma avaliação comparada da situação de cada tipo de agricultor, podendo ser averiguada a intensidade de uso da terra e a capacidade de reprodução social.

Para a avaliação da capacidade de reprodução social dos diferentes tipos, foi considerado um nível de renda mínimo para remuneração de cada Unidade de Trabalho (UT) envolvida na atividade agropecuária. Assim, para a categoria Agricultor Familiar, o Nível de Reprodução Social (NRS), foi estimado a partir de um critério externo à UPA, sendo este o montante de 13 salários mínimos auferidos ao longo do ano agrícola ${ }^{5}$, por UT. Por sua vez o NRS para os empreendedores observou a remuneração de todos os fatores de produção a um preço de mercado, ou seja, considerando o custo de oportunidade. De acordo com Kay, Edwards e Duffy (2014), o custo de oportunidade mede o rendimento potencial mínimo do capital, caso fosse investido em um empreendimento alternativo. Assim, para a definição do NRS dos empreendedores, se observou um rendimento anual mínimo de $5 \%$ de todo capital investido na atividade agropecuária.

Sobre o Nível de Reprodução Social, é importante salientar que o não alcance desse patamar, não significa o desaparecimento imediato de um determinado tipo de agricultor. Porém, demonstra uma tendência de descapitalização que pode se materializar na incapacidade de determinado tipo em se reproduzir socialmente no médio e longo prazo (SILVA NETO, 2016b).

Já o modelo linear elaborado a partir do cálculo da renda agrícola de cada tipo de produtor é expresso da seguinte forma (DUFUMIER, 2010; LIMA et al., 2005; SILVA NETO, 2016b).

\section{RA/UT $=($ PBT/ha - GP/ha $) *$ SAU/UT $)+(-$ GNP/UT $)$}

GP/ha: Gastos Proporcionais à superfície agrícola

\footnotetext{
${ }^{4}$ Cabe destacar que a SAU é considerada como o quantitativo de área disponível para o desenvolvimento das atividades produtivas, distinguindo-se assim do conceito de área total de uma UPA.

${ }^{5}$ Considerando o salário mínimo vigente em 2017, de R \$ 937,00, o NRS calculado foi de R\$12.181,00.
} 
GNP/UT: Gastos não proporcionais à superfície agrícola

Assim, os modelos confeccionados corresponderam a uma função linear representada por " $y=a x+b$ ”. O coeficiente angular " $a$ ” indica o nível de intensificação dos sistemas de produção em relação a superfície ocupada, demonstrando o potencial de geração de renda agrícola por hectare disponível. O coeficiente " $b$ ” representa a quantidade de gastos fixos por Unidade de Trabalho (UT) necessários para implementação do sistema de produção analisado. Assim, quanto mais alto o valor desse coeficiente, maior o gasto monetário de instalação do sistema de produção. Para confecção dos modelos foram considerados os resultados econômicos de uma UPA tida como representativa de cada tipo identificado.

Tal como recomendado por Dufumier (2010), o levantamento dos dados agronômicos e socioeconômicos foi realizado via uso da amostragem dirigida, em que o tamanho da amostra buscou abranger a diversidade de agricultores e de sistemas de produção reconhecidos ao longo do estudo. Assim, o número de entrevista observou o critério de saturação de informações. Para levantamento destes dados, foram entrevistados 18 produtores entre os meses de março e julho de 2017.

\section{ZONEAMENTO AGROAMBIENTAL E HISTÓRIA AGRÁRIA}

O município de Porto Vera Cruz está localizado na mesorregião Noroeste do Rio Grande do Sul, situando-se às margens do rio Uruguai, na fronteira com a Argentina. $\mathrm{O}$ município possui uma extensão de $363,7 \mathrm{~km}^{2}$ e uma população de 1.852 habitantes, dos quais $76 \%$ vivem no meio rural (IBGE, 2017). A agricultura é a principal atividade econômica do município, sendo que a agricultura familiar responde por $85 \%$ do total de estabelecimentos agropecuários (IBGE, 2018).

O zoneamento agroambiental permitiu a distinção de duas unidades de paisagem no município, sendo nomeadas como Unidade de Encosta (UE) e Unidade de Vale (UV). A Unidade de Encosta é principalmente marcada por abranger os locais com relevo declivoso. Os solos ocorrentes nesta unidade apresentam boa fertilidade natural, porém, com grandes limitantes físicos para o desenvolvimento da agricultura mecanizada. Por seu turno, a Unidade de Vale ocorre às margens do rio Uruguai e de outros rios que perpassam o município. Na paisagem esta unidade se encontra associada à Unidade de Encosta, 
ocorrendo logo em seguida ao arrefecimento do relevo. Assim, o relevo da UV varia de plano a suavemente ondulado. Os solos ocorrentes nesses locais não são profundos e apresentam uma baixa fertilidade natural. Dada a proximidade entre a UV e os leitos fluviais, uma característica diferencial desta unidade é a possibilidade de inundação nos períodos de maior precipitação. Na figura 1, é apresentada a localização do município de Porto Vera Cruz e a forma de distribuição das duas unidades na paisagem local.

Figura 1 - Localização e distribuição da Unidade de Vale e da Unidade de Encosta ao longo do município de Porto Vera Cruz

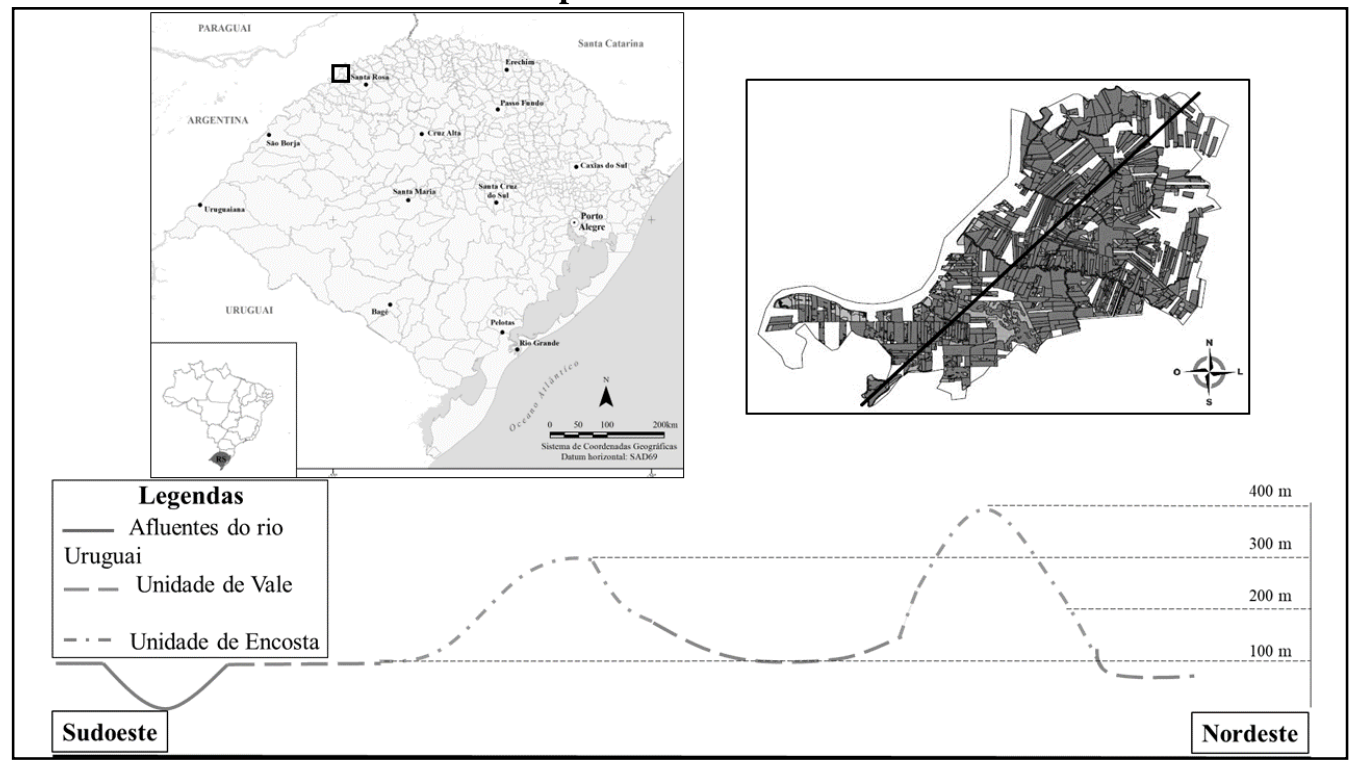

Fonte: Elaborado pelos autores (2020), a partir de FEE (2014).

Tratando-se da história agrária, cabe destacar que os indígenas foram os primeiros habitantes locais, sendo que a decadência do seu Sistema Agrário ocorreu em virtude da chegada dos imigrantes não ibéricos à região (MIGUEL et al., 2018). De todo modo, tal como ocorrido em outros municípios periféricos da região noroeste do Rio Grande do Sul, Porto Vera Cruz foi colonizado tardiamente, em que a chegada dos primeiros imigrantes ocorreu na metade do século XX. É importante destacar que a ocupação do município se deu no terceiro e último ciclo de expansão da fronteira agrícola colonizadora no estado, a qual havia sido iniciada com a chegada dos primeiros colonos alemães em São Leopoldo, mais de cem anos antes (MIGUEL, 2018; SILVA NETO; BASSO, 2015a). A pesquisa de campo evidenciou que grande parte dos primeiros colonizadores do município eram descentes de imigrantes que haviam participado das frentes de ocupação anteriores no 
Noroeste. De modo que a ocupação de Porto Vera Cruz ocorreu em virtude da necessidade de busca de novas áreas para o assentamento dos novos colonos.

A reconstituição da história da agricultura do município permitiu verificar que contrariamente ao ocorrido com as chamadas Colônias Velhas, fundadas em um raio de 200 quilômetros de Porto Alegre, e das Colônias Novas, fundadas próximas ao município de Ijuí (SILVA NETO; BASSO, 2015a), a organização da ocupação do município de Porto Vera Cruz foi feita por empresas de capital privado, não havendo amparo algum das instituições públicas. Em decorrência desta particularidade, não houve planejamento para a ocupação do território e nenhuma forma de assistência para desenvolvimento de uma infraestrutura produtiva básica no início da colonização. De todo modo, tal como ocorrido em outras frentes de colonização do Rio Grande do Sul, a ocupação do território ocorreu às custas da expulsão dos habitantes locais, em sua maioria descendentes de indígenas e negros (MIGUEL, 2018; SILVA NETO; BASSO, 2015a).

Também como ocorrido em outras colônias de imigrantes, durante as primeiras décadas de ocupação, o desenvolvimento da agricultura foi principalmente marcado pela produção para subsistência. Assim, ao menos até os anos 1970, apenas alguns agricultores realizavam a comercialização em mercados regionais, vendendo produtos como o milho, o gado de corte e suínos do "tipo banha". Nesse sentido, cabe salientar que aspectos como o baixo nível de capitalização dos agricultores imigrantes, o grande afastamento geográfico e a precária infraestrutura viária do município, bem como as limitações do próprio ecossistema cultivado, dificultaram, até os anos 1980, o desenvolvimento de sistemas de produção intensivos no uso de recursos que compunham o pacote tecnológico da Revolução Verde. De modo que, ao contrário de outros locais do noroeste do estado, Porto Vera Cruz não vivenciou uma intensificação generalizada da produção de grãos e de suínos durante as décadas de 1960 e 1970 (CALLEGARO; TREVISAN, 2015; OLIVEIRA, 2010; SILVA NETO; BASSO, 2015a). Essa dinâmica somente é parcialmente modificada nos anos 1980, quando a agricultura local passa a ter uma maior integração aos mercados, via a produção de tabaco.

Foi a partir da década subsequente, porém, que Porto Vera Cruz assiste às mudanças que moldaram as características atuais de sua agricultura. Nos anos 1990, buscando uma alternativa à produção de tabaco, a prefeitura municipal passa incentivar a produção de frutas e olerícolas no município, principalmente nos estabelecimentos inseridos na Unidade 
de Encosta. O incentivo governamental surtiu efeito e em 2002 foi fundada Cooperativa dos Agricultores de Porto Vera Cruz (COOPOVEC). Desde então a cooperativa tem desempenhando um importante papel na comercialização de hortifrutigranjeiros. Especialmente nas áreas da Unidade Vale, desde os anos 1990, nota-se que a pecuária de corte se expande, tomando o lugar da produção de suínos e de grãos. A partir dos anos 2000, por sua vez, foi a produção de leite que também passou a ter importância na agricultura, se desenvolvendo nas duas unidades de paisagem do município. O desenvolvimento dessa atividade decorreu do dinamismo desta cadeia produtiva no noroeste do Rio Grande do Sul, durante os anos 2000 e 2010 (OLIVEIRA, 2010). A partir dessa dinâmica recente da agricultura é que são conformados três tipos principais de agricultores do município. São eles, os (i) Agricultores Familiares Diversificados, (ii) Agricultores Familiares produtores de Leite e (iii) Agricultores Familiares produtores de Gado de Corte e Leite.

Em paralelo a estas dinâmicas produtivas, marcadas pela presença da agricultura familiar, uma segunda categoria social se destaca na dinâmica agrária local. Nesse sentido, dado que a agricultura sofre com o êxodo rural e com as dificuldades de sucessão familiar, a oferta de terras para venda e arrendamento tem atraído investidores externos. Tais investidores têm adquirido grande número de pequenas propriedades e se dedicado a exploração de gado de corte em sistemas extensivos e semiextensivos, em conjunto com a criação de suínos em regime integrado. Este sistema produtivo tem sido adotado por alguns agricultores familiares, de modo que além dos três primeiros tipos principais, os (iv) Empreendedores Externos e os (v) Agricultores Familiares produtores de Suínos e Gado de Corte, enquadram-se como tipologias secundárias à dinâmica da agricultura local.

\section{CARACTERIZAÇÃO DOS AGRICULTORES E PRODUTORES RURAIS DE PORTO VERA CRUZ}

Considerando os cinco tipos identificados, com base na reconstrução da história da agricultura de Porto Vera Cruz, em seguida são apresentadas suas principais características produtivas e sociais. 


\section{Agricultor Familiar Diversificado (AFD)}

O Agricultor Familiar Diversificado tem como principal característica colocar em prática sistemas de produção relacionados à produção de plantas frutícolas de clima temperado e subtropical, tais como a videira, o citros, o abacaxizeiro, a bananeira e o morangueiro. Além da fruticultura, este tipo de agricultor se dedica à olericultura, em que a produção de alface, repolho, rúcula, couve, cenoura, rabanete, beterraba, pepino, melancia e tomate destacam-se. No município de Porto Vera Cruz, estes agricultores estão principalmente inseridos na Unidade de Encosta e geralmente possuem de 5 a 15 hectares de superfície agrícola útil. A mão de obra é exclusivamente familiar, sendo ocupadas para o desenvolvimento da atividade de uma até duas unidades de trabalho. Ao menos um membro da família se dedica apenas à atividade agrícola. Os Agricultores Familiares Diversificados são aqueles que possuem a menor representatividade na região de estudo.

A comercialização da produção é realizada diretamente no município e em feiras da agricultura familiar de cidades vizinhas. Além das feiras, os mercados institucionais têm sido importantes para este tipo de agricultor. Nesses mercados, a comercialização dos produtos para o Programa Nacional de Alimentação Escolar (PNAE) e para o Programa de Aquisição de Alimentos (PAA), tem sido organizada pela cooperativa local. Além da venda de produtos in natura, a COOPOVEC tem buscado o processamento da produção de frutas dos Agricultores Diversificados. Para o funcionamento do sistema de produção, os representantes deste tipo dispõem de um nível de mecanização que varia entre tração animal e tração mecanizada. Quando mecanizada, o principal equipamento utilizado são os microtratores cultivadores. Para renovação da fertilidade do solo é comum o uso de adubação orgânica, bem como práticas agroecológicas para o controle de pragas e doenças.

\section{Agricultor Familiar produtor de Leite (AFL)}

Assim como o tipo anterior, o Agricultor Familiar produtor de Leite ocorre principalmente na Unidade de Encosta, sendo uma tipologia representativa de muitos estabelecimentos do município. A área disponível para agricultura varia de 10 a 14 hectares. A mão de obra da qual depende a unidade de produção é exclusivamente familiar, sendo que o sistema produtivo necessita de no mínimo 1,5 unidades de trabalho. Desse modo, a atividade leiteira é desenvolvida pelo casal de agricultores, havendo dedicação 
exclusiva de ao menos um dos produtores. A venda do leite é feita para cooperativas e empresas regionais, as quais recolhem o produto nas UPAs.

A reprodução dos animais é geralmente feita via inseminação artificial, sendo utilizadas raças mestiças, oriundas de cruzamentos entre raças zebuínas e raças europeias, sobretudo gado Jersey e Holandês. As pastagens plantadas fornecem grande parte da alimentação dos animais ao longo de todo ano, sendo acrescentado ração comprada fora do estabelecimento, milho produzido na propriedade e, em certos casos, silagem de milho. As instalações e benfeitorias disponíveis para a produção de leite são construídas em madeira, havendo benfeitorias específicas para ordenha. Em média o tipo Familiar Leite possui entre 10 e 12 vacas em lactação ao longo do ano, com uma produção diária que varia de 100 a 200 litros de leite. A ordenha é feita de forma mecânica utilizando ordenhadeiras do tipo "balde ao pé6", entretanto a maior parte dos produtores não dispõe de tratores.

\section{Agricultor Familiar produtor de Gado de Corte e Leite (AFGCL)}

O Agricultor Familiar produtor de Gado de Corte e Leite representa grande parte da agricultura de Porto Vera Cruz. Contudo, diferentemente dos dois tipos descritos anteriormente, estes agricultores possuem especificidades importantes em seu sistema social que incidem diretamente sobre o desenvolvimento do seu sistema de produção. Uma das especificidades se relaciona a elevada idade de membros da família ainda em atividade. Assim, em geral, há a previsão de aposentadoria de um membro da família no curto ou médio prazo, havendo casos em que um dos agricultores já se encontra recebendo este benefício social. Além disso, as UPAs desse tipo não apresentam indícios de sucessão familiar, não havendo, por consequência, possiblidades claras de continuidade da atividade agropecuária no médio e longo prazo.

Ao contrário dos tipos AFD e AFL, o Agricultor Familiar produtor de Gado de Corte e Leite está inserido principalmente na Unidade de Vale, e por conseguinte, são confrontados com as maiores restrições no ecossistema cultivado. A superfície disponível para o desenvolvimento da agropecuária varia de 20 até 35 hectares. A principal atividade produtiva desempenhada é a criação de gado de corte, sendo que aquelas unidades de produção que ainda não possuem membros aposentados, desenvolvem, em conjunto com a

\footnotetext{
${ }^{6}$ Tipo de ordenhadeira mecânica em que o leite ordenhado é inicialmente armazenado em baldes de inox. 
pecuária de corte, a produção de leite. No entanto, a perspectiva de continuidade desta atividade é limitada, uma vez que os produtores vislumbram o abandono da produção leiteira quando um dos membros da família atinja a aposentadoria. De todo modo, quando desenvolvida a produção de leite e corte, esta tipologia de agricultor necessita de duas unidades de trabalho para o desenvolvimento do sistema de produção.

Tratando-se da comercialização, a venda do gado é feita para atravessadores, enquanto a produção de leite é comercializada para empresas e cooperativas da região. A produção de gado de corte é realizada com os sistemas criação de cria, recria e engorda (ciclo completo), ou apenas com o sistema de engorda. A alimentação se baseia em pastagens naturais e sal mineral. Na maior parte das unidades de produção deste tipo os agricultores utilizam pastagens permanentes manejadas extensivamente. Quanto à produção de leite, as instalações, o tamanho dos rebanhos e os itinerários técnicos se assemelham àquele desenvolvido pelo tipo AFL. A grande diferença, porém, relaciona-se ao caráter menos intensivo da produção leiteira, sendo que geralmente os agricultores possuem uma produção diária de no máximo 100 litros. Esta tipologia não dispõe de mecanização, sendo a tração animal utilizada na maior parte dos estabelecimentos agropecuários.

\section{Agricultor Familiar produtor de Suínos e Gado de Corte (AFSGC)}

Com uma menor ocorrência no município de Porto Vera Cruz, se apresenta o Agricultor Familiar produtor de Suínos e Gado de Corte. No entanto, desde 2010, esta tipologia tem aumentado sua representatividade, nas duas unidades da paisagem identificadas. A característica principal destes agricultores se relaciona ao fato de terem uma maior capitalização e uma maior superfície agrícola útil, geralmente ultrapassando 40 hectares. Além disso, a possibilidade de acesso a recursos financeiros com uma baixa taxa de juros, via Programa Nacional de Fortalecimento da Agricultura Familiar (PRONAF), tem permitido que estes agricultores coloquem em prática sistemas de produção mais intensivos no uso de capital, tal como a produção de suínos em regime de integração em ciclo de engorda e terminação.

A produção integrada de suínos se embasa em um processo contratual, em que os produtores desenvolvem o sistema de criação seguindo técnicas e normas pré-estabelecidas, pelas empresas integradoras. Considerando o conceito de autonomia tratado por Ploeg 
(2008), dentre todos os agricultores familiares de Porto Vera Cruz o tipo AFSGC é a tipologia que possui menor autonomia, uma vez que a tomada de decisões relativa ao modo de condução do seu sistema produtivo é restrita. Além da produção integrada de suínos, esses produtores se dedicam a criação de gado de corte. Contudo, diferentemente do sistema de criação colocados em prática pelos AFGCL, esta tipologia tem intensificado o sistema de criação de gado, utilizando raças melhoradas, pastagens plantadas e uso de silagem para alimentação. O funcionamento do sistema de produção depende de duas pessoas trabalhando integralmente na atividade. Destaca-se que estes agricultores dispõem de tração motomecanizada.

\section{Empreendedor Externo}

Como destacado anteriormente, a agricultura familiar de Porto Vera Cruz vem sofrendo com a falta de sucessão familiar, de modo que inúmeros estabelecimentos têm desaparecido, ou se tornado moradia de agricultores aposentados. Tal dinâmica tem aumentado a oferta de terras, para venda ou arrendamento, e por sua vez atraído investidores externos ao município. Esses indivíduos geralmente são profissionais liberais, exercendo profissões como a de médicos, dentistas, advogados e empresários em municípios próximos à Porto Vera Cruz.

É na Unidade de Vale que a maior parte dos estabelecimentos empresariais estão instalados, sendo que o sistema de produção colocado em prática se relaciona à produção de gado de corte e de suínos no regime integrado. A condução técnica do sistema de produção ocorre de forma semelhante ao realizado no tipo AFSGC. Estes empreendedores utilizam essencialmente mão de obra contratada, possuem motomecanização e dispõem de áreas de ao menos 60 hectares.

\section{A REPRODUÇÃO SOCIOECONÔMICA DOS AGRICULTORES DE PORTO VERA CRUZ}

Reconhecidas as características dos agricultores que conformam a agricultura de Porto Vera Cruz, o gráfico 1 apresenta os resultados econômicos das quatro tipologias de agricultores familiares verificadas. A análise comparada dos resultados econômicos permite 
inferir que todos os tipos de agricultores familiares possuem rendimentos agrícolas próximos ao Nível de Reprodução Social, sendo que os tipos Agricultor Familiar Diversificado (AFD) e o Agricultor Familiar Suínos Gado de Corte (AFSGC), dispõem das melhores remunerações da mão de obra. Como já salientado, mesmo que o não alcance do NRS não determine, no curto prazo, o desaparecimento da unidade de produção agropecuária, ou o fim do próprio sistema de produção, a avaliação comparada entre as tipologias permite avaliar quais agricultores se encontram com maior e menor dificuldade de reprodução social. Nesse sentido, uma análise pormenorizada dos resultados econômicos e da reprodução social de cada tipologia cabe ser feita.

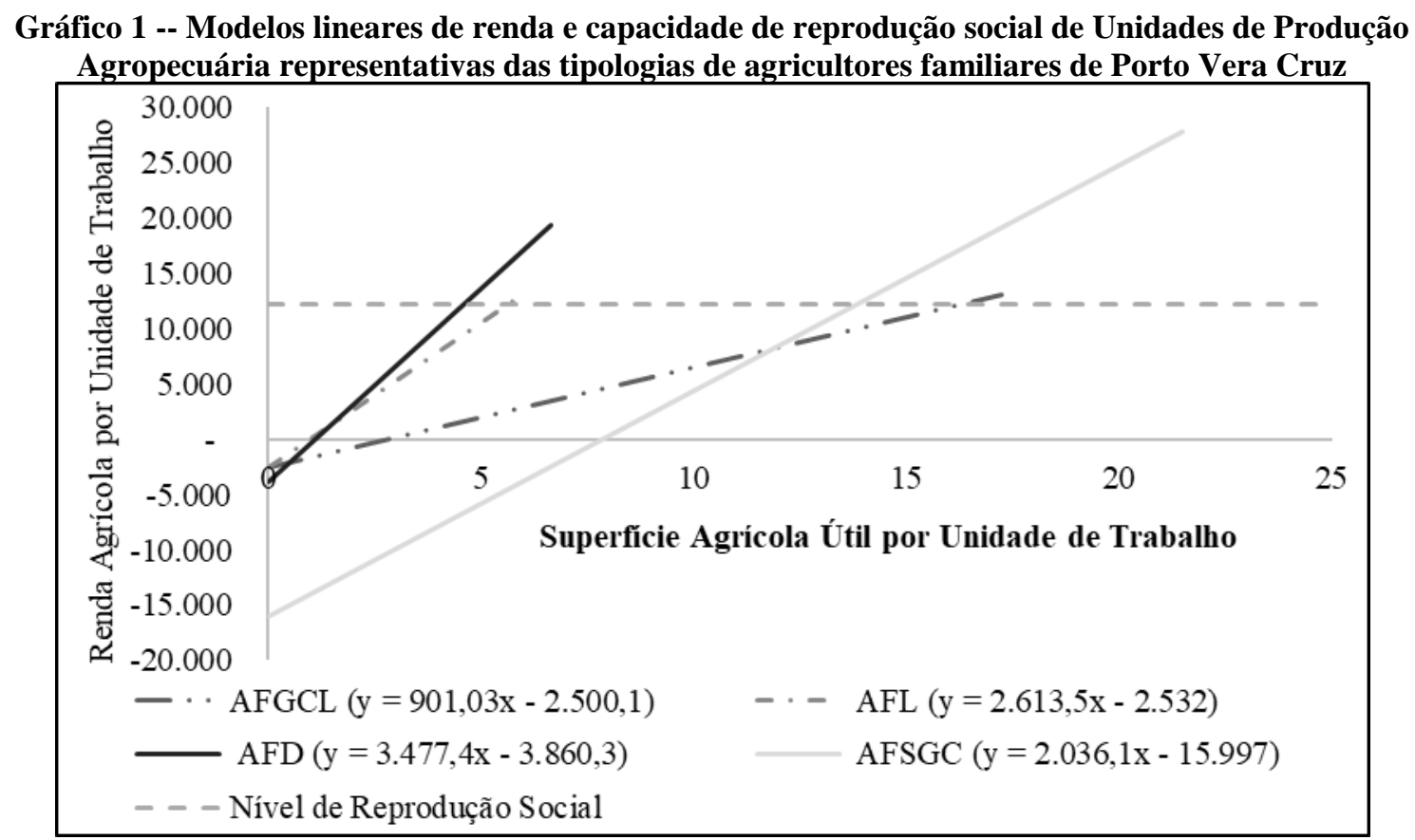

Fonte: Elaborado pelos autores com base nos dados de pesquisa (2017).

O tipo Agricultor Familiar Diversificado (AFD), é o tipo que possui o sistema de produção com maior capacidade de geração de renda por unidade de área, apresentando um coeficiente "a" de 3.477. A intensidade do sistema produtivo se dá em decorrência da baixa disponibilidade de terra desses produtores, que varia de 5 até 7 hectares por trabalhador ocupado na atividade. Os gastos para colocar em prática o sistema de produção Diversificado, "coeficiente b", se assemelham às despesas monetárias para o desenvolvimento da atividade leiteira, nos moldes produtivos desenvolvidos pelo tipo 
Agricultor Familiar Leite (AFL). Tal indicador demonstra o caráter inclusivo desse sistema de produção, uma vez que os gastos para sua implementação não são altos.

Mesma característica produtiva foi observada por Tonin (2018) em estudo realizado no município de Rolador, no Rio Grande do Sul. Tal como ocorrido em Porto Vera Cruz, naquele município eram também os produtores com menores áreas os que se dedicavam ao desenvolvimento de sistemas de produção relacionados com a horticultura. De igual forma ao apresentado aqui, ao analisar os sistemas de produção de Pinheirinho do Vale, no norte do Rio Grande do Sul, Lima et al. (2020) destacaram grande capacidade de geração de riquezas destes sistemas de produção. Contudo, deve ser destacado que no município de Porto Vera Cruz, a expansão dos produtores deste tipo é dificultada em decorrência do baixo número de canais de comercialização acessados, que como visto tem se limitado às feiras locais e regionais e aos mercados institucionais. Nesse sentido, a diminuição do orçamento destinado ao PAA, desde 2012, e a descontinuidade dos projetos vinculados ao programa (PROCEDI, 2019) podem ocasionar dificuldades de reprodução social para estes agricultores.

O baixo gasto monetário para colocar em prática o sistema de produção de leite, bem como a maior facilidade de escoamento da produção, são aspectos que fazem do AFL um dos tipos com grande representatividade numérica no município. Igual aos Agricultores Diversificados estes produtores possuem limitações na área disponível para a agricultura. No entanto, em comparação com o tipo AFD, esta tipologia apresenta um sistema de produção menos intensivo na geração de renda por área ocupada, com coeficiente "a" de 2.613. Assim, para o alcance do NRS os Agricultores Familiares produtores de Leite precisam de mais de 5 hectares de superfície agrícola útil disponível para cada membro da família envolvido na atividade. Além das limitações de área para a produção, esta tipologia tem sofrido com a dinâmica do mercado agroindustrial de leite, que constantemente tem exigido dos produtores aumentos na escala produtiva (BÁNKUTI; CALDAS, 2018; MARKS MACHADO, 2019). Considerando as limitações de área disponível nos estabelecimentos, a pressão por intensificação tende a se desdobrar na necessidade de maiores investimentos em insumos produtivos externos à UPA. De modo que a imposição de mudança no sistema produtivo pode tanto diminuir o caráter inclusivo da atividade, como também pode representar a exclusão daqueles agricultores familiares que não dispuserem de meios para intensificação dos seus sistemas de produção. 
É importante salientar que as características produtivas e econômicas dos AFL do município de Porto Vera Cruz, diferem do perfil produtivo de produtores de leite em outras regiões do noroeste do Rio Grande do Sul. Podendo ser apresentadas duas diferenças principais. Primeiro, ao contrário do ocorrido em outros municípios do noroeste gaúcho a atividade leiteira no município não é desenvolvida de forma conjunta com a produção de grãos (DEON; AZEVEDO; NETTO, 2017; MARKS MACHADO; TONIN; SILVA NETO, 2016; SILVA NETO; BASSO, 2015b). Além disso, como demonstram os resultados socioeconômicos, a produção de leite desenvolvida pelo AFL é menos dependente de insumos externos às UPAs, reafirmando o caráter inclusivo e diferencial desta atividade em Porto Vera Cruz (DEON; AZEVEDO; NETTO, 2017; SILVA NETO, 2014).

Diferente do AFL e do AFD, o tipo Agricultor Familiar produtor de Gado de Corte e Leite (AFCL) possui para o desenvolvimento de seu sistema de produção uma maior área disponível, sendo que para cada unidade de trabalho estes produtores detêm de 15 a 20 hectares. Como pode ser visualizado no gráfico 1, o coeficiente angular "a" é de pouco mais de 900, demonstrando o caráter extensivo deste sistema de produção agropecuário. Embora no gráfico 1 possa ser visualizado que a UPA tratada como representativa deste tipo de agricultor alcança o nível de reprodução estipulado, é importante ressalvar que isso ocorre apenas quando os produtores exploram a produção de gado de corte em conjunto com a pecuária leiteira. Assim, aquelas unidades produtivas que já possuem ao menos um membro aposentado e que deixam a produção de leite, não dispõem de renda agrícola suficiente para o alcance do NRS. Essa dinâmica demonstra a importância da produção leiteira para a reprodução social da agricultura de Porto Vera Cruz, uma vez que os tipos AFL e AFGCL representam a maior parte dos agricultores familiares do município.

Quanto ao Agricultor Familiar produtor de Suínos Gado de Corte (AFSGC), a característica que distingue estes dos demais tipos familiares, decorre dos mais altos gastos necessários para a implantação e funcionamento de seu sistema de produção. Como pode ser visualizado no gráfico 1, o custo de implantação deste sistema produtivo, representado pelo coeficiente "b", chega a 15.997. A comparação entre os modelos permite inferir que o sistema de produção desenvolvido pelo tipo AFSGC, possui custos monetários quatro vezes superior ao do sistema de produção colocado em prática pelo tipo Agricultor Familiar Diversificado. Considerando que os investimentos necessários para a produção de suínos e 
gado de corte não são acessíveis à grande parte dos produtores, este sistema de produção não pode ser considerado um sistema de produção inclusivo. Junto a isso, como também pode ser visto pelo gráfico 2, a tipologia AFSGC necessita de maiores áreas para colocar em prática o seu sistema produtivo e se reproduzir socialmente, de modo que para cada unidade de trabalho envolvida na atividade são necessárias em torno de 15 hectares.

O gráfico 2 demonstra o modelo linear para unidade de produção representativa do tipo Empreendedor. Diferente dos outros quatro tipos familiares identificados, a avaliação da reprodução socioeconômica fez uso do custo de oportunidade de todos os fatores de produção.

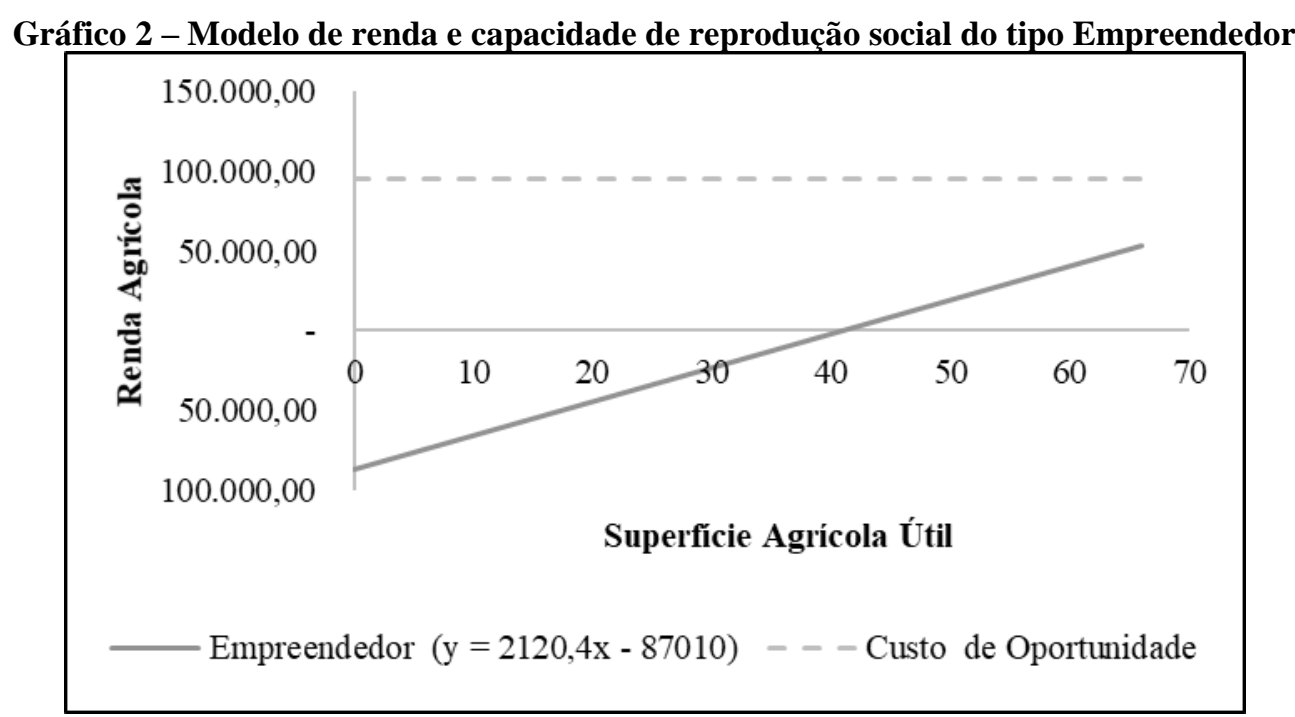

Fonte: Elaborado pelos autores com base nos dados de pesquisa (2017).

Dada a similaridade entre os sistemas de produção do tipo Empreendedor e do AFSGC a análise dos dados econômicos demonstrou que o potencial de geração de renda por área ocupada entre os dois tipos é similar. Porém, a UPA empresarial apresenta maiores gastos monetários para colocar em prática o seu sistema de produção, dado que necessita remunerar a mão de obra contratada. Considerando um custo de oportunidade anual de $5 \%$ do capital total investido, nenhuma das unidades empreendedoras obtiveram rendimentos suficientes para alcançar o nível de reprodução social. Dada a baixa remuneração agrícola obtida pelos empreendedores em conjunto com a baixa liquidez do capital investido na agropecuária, o comportamento destes agentes, que tem expandido a compra de terras no município, pode estar de alguma forma relacionada a uma estratégia de compra da terra 
como um ativo de valorização futura. Ou seja, o interesse econômico desses investidores pode estar mais relacionado ao uso da terra como uma forma de reserva de valor.

\section{CONSIDERAÇÕES FINAIS}

Como exposto inicialmente, este artigo teve como objetivo analisar as estratégias produtivas e as possibilidades de reprodução social dos diferentes tipos de agricultores que compõem a agricultura do município de Porto Vera Cruz. O estudo permitiu averiguar que as principais modificações que delinearam as estratégias produtivas na agricultura do município, remontam a década de 1990. De todo modo, é notável que tanto os aspectos históricos, como também as características das unidades de paisagem verificadas, contribuíram para a conformação das estratégias mobilizadas pelos quatro tipos de agricultores familiares e o tipo de empreendedor identificado.

Enquanto pode ser dito que os condicionantes históricos interferiram no desenvolvimento tardio da agropecuária do município, as características das unidades da paisagem foram fundamentais para espacialização da agricultura local. Assim, o estudo constatou que enquanto os Agricultores Familiares Diversificados e Agricultores Familiares produtores de Leite se encontram principalmente inseridos na Unidade de Encosta, os Empreendedores Externos e os agricultores que tem produzido gado de corte estão em sua maioria presentes na Unidade de Vale. De modo que os sistemas produtivos mais intensivos na geração de riquezas, são característicos da Unidade de Encosta.

Quanto a reprodução social, os dados socioeconômicos permitiram inferir que a agricultura porto vera-cruzense apresenta dinamismo econômico, de modo que todos os tipos de agricultores familiares identificados pelo o estudo possuem renda agrícola próxima ao nível de reprodução social. No entanto, algumas especificidades puderam ser explicitadas em relação a situação dos diferentes tipos de agricultores familiares. Embora o tipo Agricultor Familiar Diversificado apresente uma estratégia produtiva economicamente viável e socialmente inclusiva, o baixo número de canais de comercialização se coloca como impeditivo à expansão do número de estabelecimentos deste tipo no município. Por seu turno, a problemática que perpassa as duas tipologias produtoras de leite se relaciona com as constantes exigências de incremento da escala de produção, impostas pelo sistema agroindustrial lácteo. Já a estratégia produtiva mobilizada pelos Agricultores Familiares 
produtores de Suínos e Gado de Corte se caracteriza pela necessidade de altos investimentos monetários e por uma baixa autonomia produtiva, sendo uma estratégia agrícola pouco viável para a grande maioria dos produtores do município.

Embora deva ser entendida como uma problemática transversal a todos os tipos de agricultores, a sucessão familiar tem dificultado, sobretudo, a manutenção das unidades de produção do tipo Agricultor Familiar produtor de Gado de Corte e Leite. A desativação destes estabelecimentos agropecuários tem atraído empreendedores à agricultura de Porto Vera Cruz, que colocam em prática sistemas de produção altamente dependentes de insumos e pouco lucrativos. Por fim, cabe pontuar que ao permitir o entendimento das estratégias produtivas e de uma interpretação crítica dos resultados socioeconômicos, a abordagem utilizada por este trabalho pode trazer contribuições significativas ao planejamento de ações em prol do desenvolvimento rural.

\section{REFERÊNCIAS BIBLIOGRÁFICAS}

BÁNKUTI, F. I.; CALDAS, M. M. Geographical milk redistribution in Paraná State, Brazil: Consequences of institutional and market changes. Journal of Rural Studies, v. 64, n. October, p. 63-72, 2018.

BENTO, J. A. N. et al. Dinâmica e Diferenciação de Sistemas de Produção no Semiárido Brasileiro: Agriculturas do Município de Pentecoste, Ceará. Desenvolvimento em Questão, v. 15, n. 41, p. 416-456, 21 out. 2017.

CALLEGARO, S. S.; TREVISAN, L. P. Análise-Diagnóstico da agricultura de Santa Rosa. In: SILVA NETO, B.; BASSO, D. (Eds.). . Sistemas Agrários do Rio Grande do Sul: análise e recomendações de políticas. $2^{\text {a }}$ ed. Ijuí: Editora da Unijuí, 2015.

DEON, P. R. C.; AZEVEDO, L. F.; NETTO, T. A. A Produção de Grãos como Estratégia de Reprodução da Agricultura Familiar: Reflexões a partir do caso do Município de Novo Machado-RS. Desenvolvimento em Questão, v. 15, n. 38, p. 261, 2017.

DUFUMIER, M. Projetos de desenvolvimento agrícola: manual para especialistas. $3^{\mathrm{a}}$ ed. Salvador: Editora da UFBA, 2010.

FEE. Mapa Fundação de Economia e Estatística (FEE). Disponível em: <http://feedados.fee.tche.br/feedados/\#!pesquisa=0>. Acesso em: 5 set. 2017.

GUANIZIROLI, C. E. Análise Diagnóstico de Sistemas Agrários. Brasília: Convênio INCRA/FAO, 1999.

IBGE. IBGE Cidades. Disponível em: <https://cidades.ibge.gov.br/brasil/pa/eldorado-docarajas/pesquisa/38/46996?localidade1=150553>. Acesso em: 29 jun. 2020. 
IBGE. Censo Agropecuário 2017 - Número de estabelecimentos agropecuários com bovinos, Efetivos, Venda e Produção de leite, por direção dos trabalhos do estabelecimento agropecuário e origem da orientação técnica recebida - resultados preliminares 2017. Disponível em: 〈https://sidra.ibge.gov.br/Tabela/6782\#notas-tabela〉.

KAY, R. D.; EDWARDS, W.; DUFFY, P. Gestão de Propriedades Rurais. 7. ed. Porto Alegre: Bookman, 2014.

LIMA, A. J. P. et al. Dinâmica Agrária e Estratégias de Desenvolvimento da Agricultura: uma análise em termos de Sistemas Agrários no Município de Pinheirinho do Vale. IGepec, v. 24, n. 2, p. 213-231, 2020.

LIMA, A. J. P. DE et al. Administração da Unidade de Produção Familiar: Modalidades de Teabalho com Agricuultura. 3 ed. Ijuí: Editora da Unijuí, 2005.

LIMA, F. A. X. et al. A Reprodução Socioeconômica na Agricultura Familiar: uma análise da Pecuária Extensiva na Capela do Caravágio-RS. Redes, v. 20, n. 3, p. 94, 2016.

MARKS MACHADO, J. T. Mudanças Socioprodutivas na Pecuária Leiteira: uma leitura a partir dos ordenamentos e dispositivos institucionais, artefatos e práticas. II Workshop Estratégias de Alimentação e Abastecimentos. Anais...Porto Alegre: Anais do II Workshop Estratégias de Alimentação e Abastecimentos, 2019

MARKS MACHADO, J. T.; TONIN, J.; SILVA NETO, B. Situação e perspectivas da agricultura do município de Cerro Largo (RS): um estudo baseado na análisediagnóstico de sistemas agrários. Anais do $11^{\mathrm{a}}$ Congresso da Sociedade Brasileira de Sistemas de Produção. Anais...Pelotas: SBPS, 2016

MAZOYER, M.; ROUDART, L. História das agriculturas no mundo: do neolítico à crise contemporânea. Porto Alegre: Editora da UFRGS, 2010.

MIGUEL, L. Abordagem sistêmica da unidade de produção agrícola. In: WAGNER, A. . et al. (Eds.). . Gestão e planejamento de unidades de produção agrícola. I ed. Brasilia, DF: UAB/UFRGS, 2010. p. 11-18.

MIGUEL, L. DE A. Sistemas Agrários e Desenvolvimento Rural. In: CONTERATO, M. A.; RADOMSKY, G. F. W.; SCHNEIDER, S. (Eds.). . Pesquisa em Desenvolvimento Rural: Aportes Teóricos e Proposições Metodológicas. Porto Alegre: Editora da UFRGS, 2014.

MIGUEL, L. DE A. Dinâmica e Diferenciação de Sistemas Agrários. 2. ed. Porto Alegre: Editora da UFRGS, 2018.

MIGUEL, L. DE A. et al. Abordagem Sistêmica e Sistemas Agrários. In: Material didático: DERAD 102. 1. ed. Porto Alegre: Curso superior Desenvolvimento Rural PLAGEDER, 2018. p. 1-47.

NEUMANN, P. S.; FIALHO, M. A. V. Sistemas agrários: Agricultura Familiar e Sustentabilidade. 1. ed. Santa Maria: Editora da UFSM, 2009. 
OLIVEIRA, A. O Padrão Tecnológico na Produção de Leite o Desenvolvimento Rural: uma análise baseada nos sitemas de produção do mnicípio de Ijuí. $2010137 \mathrm{f}$.

Dissertação (Mestrado em Desenvolvimento Regional) Universidade Regional do Noroeste do Estado do Rio Grande do Sul, Ijuí 2010.

PLOEG, J. D. VAN DER. Camponeses e Impérios Alimentares. Porto Alegre: Editora da UFRGS, 2008.

PROCEDI, A. A Trajetória do Programa de Aquisição de Alimentos (PAA) no Rio Grande do Sul: Entre a Descontinuidade da Política Pública e a Capacidade de Ação dos Atores Sociais. 2019. 142 f. Dissertação (Mestrado em Desenvolvimento Rural) Universidade Federal do Rio Grande do Sul, Porto Alegre, 2019.

SILVA NETO, B. Sistemas Agrários e Agroecologia: a dinâmica da agricultura e as condições para uma transição agroecológica no município de Porto Xavier (RS). Revista Brasileira de Agroecologia, v. 9, n. 2, p. 15-29, 2014.

SILVA NETO, B. Agroecologia e Análise Econômica de Sistemas de Produção: Uma análise baseada no materialismo histórico e dialétic. Chapecó: Editora da UFFS, $2016 \mathrm{a}$.

SILVA NETO, B. Agroecologia e Análise Econômica de Sistemas de Produção: uma abordagem baseada no materialismo histórico e dialético. Cerro Largo: Editora da UFFS, $2016 b$.

SILVA NETO, B.; BASSO, D. Sistemas Agrários do Rio Grande do Sul. Análise e Recomendações de Políticas. $2^{\text {a }}$ ed. Ijuí: Editora da Unijuí, 2015 a.

SILVA NETO, B.; BASSO, D. Sistemas Agrários do Rio Grande do Sul: análise e recomendações políticas. 2. ed. Ijuí: Editora da Unijuí, 2015 b.

TONIN, J. A Agricultura de Rolador e a Concentração Produtiva: Uma Análise dos Sistemas de Produção de Leite. 2018, 152 f. Disssertação (Mestrado em Desenvolvimento Rural) Universidade Federal do Rio Grande do Sul, Porto Alegre, 2018.

WIVES, D. G. Funcionamento e Performance dos Sistemas de Produção da Banana na Microrregião do Litoral Norte do Rio Grande do Sul. 2008, 164 f. Disssertação (Mestrado em Desenvolvimento Rural) Universidade Federal do Rio Grande do Sul, Porto Alegre, 2008. 